\title{
Geração de cenários através de simulação computacional como instrumento da mobilidade urbana
}

\author{
Generation of scenarios through computer simulation as an instrument of urban \\ mobility
}

\author{
Fernando Dutra Silva ${ }^{1}$; Viviane Adriano Falcão²; Antônio Carlos Evangelista ${ }^{3}$ \\ ${ }^{1}$ Graduado em Engenharia Civil, Universidade Federal do Triângulo Mineiro, Uberaba, Minas Gerais, Brasil. \\ Orcid: https://orcid.org/0000-0002-9565-8651. E-mail: dutra_fernando@hotmail.com \\ 2Universidade Federal do Pernambuco, Recife, Pernambuco, Brasil. \\ Orcid: https://orcid.org/0000-0003-0850-4281. E-mail: viviane.afalcao@ufpe.br \\ ${ }^{3}$ Universidade Federal de Uberlândia, Uberlândia, Minas Gerais, Brasil. \\ Orcid: https://orcid.org/0000-0002-7450-8689. E-mail: antonio.evanger@gmail.com
}

\begin{abstract}
RESUMO: O aumento significativo da frota de veículos no Brasil acarretou algumas externalidades urbanas, há algumas, porém que tem uma influência direta na qualidade de vida da população economicamente ativa, que são os congestionamentos. O objetivo desse estudo foi estabelecer a otimização semafórica na região do entorno do Hospital de Clínicas da Universidade Federal do Triângulo Mineiro (HC-UFTM) em Uberaba e a partir disso promover melhorias na mobilidade urbana do entorno. Para tanto, foi feito uma contagem volumétrica em cinco interseções no entorno do HC-UFTM e, posteriormente a caracterização das mesmas de acordo com dois manuais desenvolvidos pelos DNIT e CONTRAN. Os dados coletados foram inseridos no software Traffic Software Integrator System TSIS 6, e processados considerando o cenário atual e as propostas de melhoria. $\mathrm{Na}$ análise dos cenários, conseguiu-se uma melhoria no desempenho de todos os parâmetros considerados, mais especificamente aumentou a taxa de movimento e a velocidade média de deslocamento e uma diminuição média da fila máxima de veículos nas interseções. Os resultados encontrados foram validados considerando o cenário atual e para os cenários otimizados, algumas medidas simples como alteração do tempo de ciclo podem otimizar o fluxo de veículos na região.
\end{abstract}

Palavras-chave: engenharia de tráfego, engenharia de transportes, otimização semafórica, simulação de tráfego.

ABSTRACT: The significant increase in the vehicle fleet in Brazil has caused some urban externalities, there are some, but it has a direct influence on the quality of life of the economically active population, which are congestion. The aim of this study was to establish traffic optimization in the region surrounding the Hospital de Clínicas of the Federal University of Triângulo Mineiro (HC-UFTM) in Uberaba and from there promote improvements in the urban mobility of the surroundings. For this purpose, a volumetric count was made at five intersections around the HC-UFTM and, subsequently, their characterization according to two manuals developed by DNIT and CONTRAN. The collected data were inserted into the Traffic Software Integrator System - TSIS 6 software, and processed considering the current scenario and the proposals for improvement. In the analysis of the scenarios, an improvement in the performance of all the considered parameters was achieved, more specifically it increased the movement rate and the average speed of displacement and an average decrease of the maximum line of vehicles in the intersections. The results found were validated considering the current scenario and for the optimized scenarios, some simple measures such as changing cycle time can optimize the flow of vehicles in the region.

Keywords: traffic engineering, transport engineering, traffic light optimization, traffic simulation. 


\section{INTRODUÇÃO}

Em uma análise dos últimos dez anos, de janeiro de 2007 até dezembro de 2017, a frota de veículos no Brasil aumentou, nesse período, de 45.653.808 para 97.091.956, ou seja, mais que dobrou de tamanho (DENATRAN, 2007, 2017).

No entanto, de acordo com Cucci Neto (2015) a sinalização de trânsito no Brasil frequentemente é tratada de forma superficial podendo chegar ao ponto de ir contra a legislação vigente. Consequência disso é a observação de filas e congestionamentos em diferentes locais dentro dos centros urbanos. Mendes e Sorratini (2014) consideram que esse problema também pode ser provocado pela ocupação desordenada das áreas urbanas, portanto, é preciso minimizá-lo com o auxílio de mecanismos juntamente com planejamento.

Dado o aumento significativo da frota de veículos no País e a deficiência da sinalização de trânsito, a otimização das sinalizações se faz de grande interesse dentro das melhorias que podem ser atingidas dada correta utilização e calibração de intercessões semafóricas como é citado pelo autor Licínio da Silva Portugal (2005).

De acordo com Soares (1975) entre as causas diretas para o aparecimento de congestionamentos está a ausência ou incorreto uso de instalações de controle de tráfego, como um do mais importantes: os semáforos. E como possível forma de solucionar o problema, o mesmo autor afirma que, de acordo com as maiores ou menores demandas de tráfego a regulagem apropriada dos semáforos podem diminuir ou, até mesmo, eliminar 0 congestionamento.

Como a região de estudo ampara dois campi de universidade, três escolas, uma biblioteca, o Hospital de Clínicas da Universidade Federal do Triângulo Mineiro (HC-UFTM), que atende Uberaba e mais 26 municípios que compõem a macrorregião Triângulo Sul do estado de Minas Gerais (HC-UFTM, 2017), e ainda possui outros polos geradores de viagem, a demanda de tráfego nessa área é elevada e como consequência gera congestionamentos em horários de pico

Este trabalho teve como objetivo otimizar os semáforos no entorno do Hospital de Clínicas da Universidade Federal do Triângulo Mineiro em Uberaba, Minas Gerais, através de simulação de tráfego utilizando o software de simulação Traffic Software Integrator System (TSIS).

\section{REVISÃO DA LITERATURA}

Até o ano de 2003 o conceito de Polos Geradores de Tráfego (PGT) advinha de diversos estudos que o caracterizam como sendo empreendimentos que geram grande número de viagens (KNEIB; SILVA; PORTUGAL, 2010). Entretanto, o conceito que antes abrangia o tráfego individual, motorizado e gerados pelos empreendimentos, passou a considerar as viagens em geral e os impactos no desenvolvimento socioeconômico e os gerados pelo polo (KNEIB; TACO; SILVA, 2009).

Após o ano de 2005, esse novo conceito cresceu no âmbito nacional e passou a ser conhecido como Polo Geradores de Viagens (PGVs), sendo definido como equipamentos potenciais geradores de impacto nos sistemas viário e de transportes e suas inter-relações na qualidade de vida da população e desenvolvimento socioeconômico. Portanto, os PGVs associado a área espacial da cidade contribui para a formação de novas centralidades urbanas, como também podem impactar de forma positiva a região, como o aumento do 
fluxo de pessoas e o surgimento de novos mercados e empreendimentos, valorização fundiária e expansão dos limites de um município (KNEIB, SILVA, PORTUGAL, 2010).

De acordo com o Departamento Nacional de Infraestrutura de Transporte - DNIT (2006) o objetivo dos estudos de tráfego é obter dados de cinco elementos principais do tráfego (motorista, pedestre, veículo, via e meio ambiente) e suas inter-relações através de métodos de coleta.

Através desses estudos pode-se saber os locais de onde se originam e para onde se destinam os veículos. Assim, por meio desses conhecimentos de como se forma a geração e distribuição do tráfego, é possível obter o diagnóstico do cenário atual e suas necessidades futuras (DNIT, 2006).

O Manual de estudos de tráfego do Departamento Nacional de Infraestrutura de Transportes (DNIT, 2006) e o Manual Brasileiro de Sinalização de Trânsito Volume V Sinalização Semafórica do Conselho Nacional de Trânsito (CONTRAN, 2014), com objetivo de uniformizar a terminologia sobre a matéria, fornece alguns conceitos gerais, como o fator horário de pico (FHP) sendo o volume da hora de pico do período de tempo considerada, dividida pelo quádruplo do volume de quinze minutos da hora de pico com maior fluxo de tráfego. O volume de tráfego representa o número de veículos que passam por uma seção de uma via, ou de uma determinada faixa, durante um intervalo de tempo. O tempo de ciclo é a sequência completa das indicações de uma sinalização semafórica. O tempo de ciclo é o tempo necessário para que um ciclo inteiro seja cumprido em uma interseção.

Para a avaliação do tráfego é feita uma simulação cujo principal propósito é o de representar, através de modelos, as interações entre os elementos de um sistema e avaliar seu desempenho. Portanto a simulação é uma poderosa ferramenta que um analista pode usar para determinar qual o melhor sistema deve ser implementado ou melhorado. Com ela diversas mudanças podem ser feitas no sistema e inclusive mensurar os efeitos dessas mudanças no mesmo (PORTUGAL, 2005).

No caso de simulações de tráfego, existem três abordagens: macroscópica, mesoscópica e microscópica. Neste estudo foi utilizada a microscópica no qual cada veículo carrega todas as características de interesse no estudo e eles têm comportamentos individualizados e independentes uns dos outros (PORTUGAL, 2005).

\section{PROCEDIMENTOS METODOLÓGICOS}

Trata-se de um estudo de abordagem quantitativo. Foram selecionadas cinco interseções próximas ao Hospital de Clínicas da Universidade Federal do Triângulo Mineiro (HC-UFTM), Uberaba, Minas Gerais, que foram identificadas como responsáveis por escoar o fluxo de veículos que trafegam no entorno da área de estudo.

As interseções avaliadas foram: interseção 1 - Avenida Getúlio Guaritá e Rua da Constituição; interseção 2 - Avenida Getúlio Guaritá com Praça Doutor Thomaz Ulhôa e Rua Castro Alves; interseção 3 - Rua Madre Maria José com Rua Padre Jerônimo e Rua dos Andradas; interseção 4 - Rua José de Alencar e Rua Frei Paulino e interseção 5 - Praça Doutor Thomaz Ulhôa com Rua Madre Maria José e Rua Carlos Rodrigues da Cunha.

A região de estudo ampara dois campi de universidade, três escolas, uma biblioteca, o HC-UFTM, que atende Uberaba e mais 26 municípios que compõem a macrorregião Triângulo Sul do estado de Minas Gerais (HC-UFTM, 2017).

Os critérios de inclusão foram veículos motorizados terrestres, sendo eles motos, carros, vans, caminhões e ônibus. Os critérios de exclusão foram veículo não motorizados 
como a bicicleta, pedestres, o período da semana de sexta-feira a segunda-feira, dias chuvosos, feriados e férias escolares, devido ao baixo fluxo de tráfego nas vias, e a interferência de acidentes de trânsito próximos as interseções analisadas.

A coleta de dados ocorreu em cada uma das interseções do estudo entre os dias da semana de terça-feira a quinta-feira, por um período de quinze horas compreendido entre as seis horas e trinta minutos até as vinte e uma horas e trinta minutos, durante o período de março e abril de 2018. Foi necessário caracterizar cada uma das interseções e para essa finalidade utilizou-se de uma câmera filmadora, pelo método da contagem por videoteipe, para registrar os dados necessários. Todas elas foram tratadas de forma isoladas, pois estão distantes umas das outras ou sofrem influência de outras vias.

A contagem por videoteipe é um método no qual o local de estudo é filmado por uma câmera de vídeo. Esse método também apresenta um elevado nível de confiança pois mesmo em situações de muito congestionamento é possível extrair dados com pequena margem de erro. Além disso os dados ficam registrados para posterior conferência, caso seja necessária alguma revisão. A desvantagem desse método é que ele passa pela contagem manual após a captura das imagens (DNIT, 2006).

Após as filmagens das interseções o volume de tráfego foi obtido através de contagem manual discriminado os sentidos dos movimentos realizados pelos veículos. Para a análise dos dados utilizou-se um computador com licença do Windows 10 Pro. Processador Intel ${ }^{\circledR}$ Core $^{\mathrm{TM}} \mathrm{i} 7-4770$ CPU @ 3.40GHz. Memória RAM: 8,00GB. Tipo de sistema 64bits.

A análise foi obtida através da comparação de cenários gerados pelo software Traffic Software Integrator System - TSIS 6, licença da versão 6, sendo dividida em três etapas. A primeira etapa foi simular o cenário atual, compreendido como o resultado final da simulação dos dados coletados em campo. Nesta etapa o software fornece parâmetros para diferentes tipos de estudos e para esta pesquisa os parâmetros adequados foram o de velocidade média de deslocamento, a taxa de movimento, que representa a razão entre 0 tempo que os veículos estiveram circulando sobre o tempo que eles ficaram circulando mais o tempo parados e a quantidade máxima de veículos que ficaram em fila.

A segunda etapa foi a geração de cinco cenários para cada interseção, totalizando 25 novos cenários. Entre os parâmetros de entrada (FHP, volume de tráfego e tempo de ciclo) a única variável mutável neste estudo foi o tempo de ciclo, logo definiu-se como cenário 1 a diminuição de cinco segundos no tempo de ciclo; o cenário 2 como aumento de cinco segundos no tempo de ciclo; cenário 3 como aumento de 10 segundos no tempo de ciclo; cenário 4 como aumento de 15 segundos no tempo de ciclo e cenário 5 como aumento de 20 segundos no tempo de ciclo. Em todos os cenários a diminuição ou aumento de tempo foi no tempo de ciclo em relação ao cenário atual.

A terceira etapa consistiu na comparação dos resultados obtidos na segunda etapa com os resultados da primeira etapa. Definiu-se como cenário otimizado, aquele em que houve o maior aumento percentual de velocidade média e taxa de movimento e diminuição percentual da quantidade máxima de veículos em fila.

\section{RESULTADOS E DISCUSSÃO}

Na interseção 1 o maior fator horário de pico foi de 0,96 e aconteceu entre as 14:08 e 15:08 do dia 13 de março de 2018. Através das filmagens foi possível obter o tempo de ciclo dos três semáforos que controlam o fluxo de veículos dessa região. Os ciclos dos 
semáforos são de 21 segundos para o semáforo $A$ (que controla o fluxo de veículos que realizam os movimentos 6-2 e 6-4), de 24 segundos para o semáforo B (que controla o fluxo de veículos que realizam os movimentos 3-4 e 3-5) e de 18 segundos para o semáforo $C$ (que controla o fluxo de veículos que realizam os movimentos 1-2 e 1-4 e 1-5) conforme a Figura 1. Com esses dados foi possível gerar o cenário atual dessa interseção e obter como velocidade média $29,34 \mathrm{~km} / \mathrm{h}$, taxa de movimento de 0,72 e a soma de veículos em fila atinge um máximo de 29 veículos.

Figura 1. Croqui de representação dos movimentos possíveis, distintos por cores, na interseção 1.

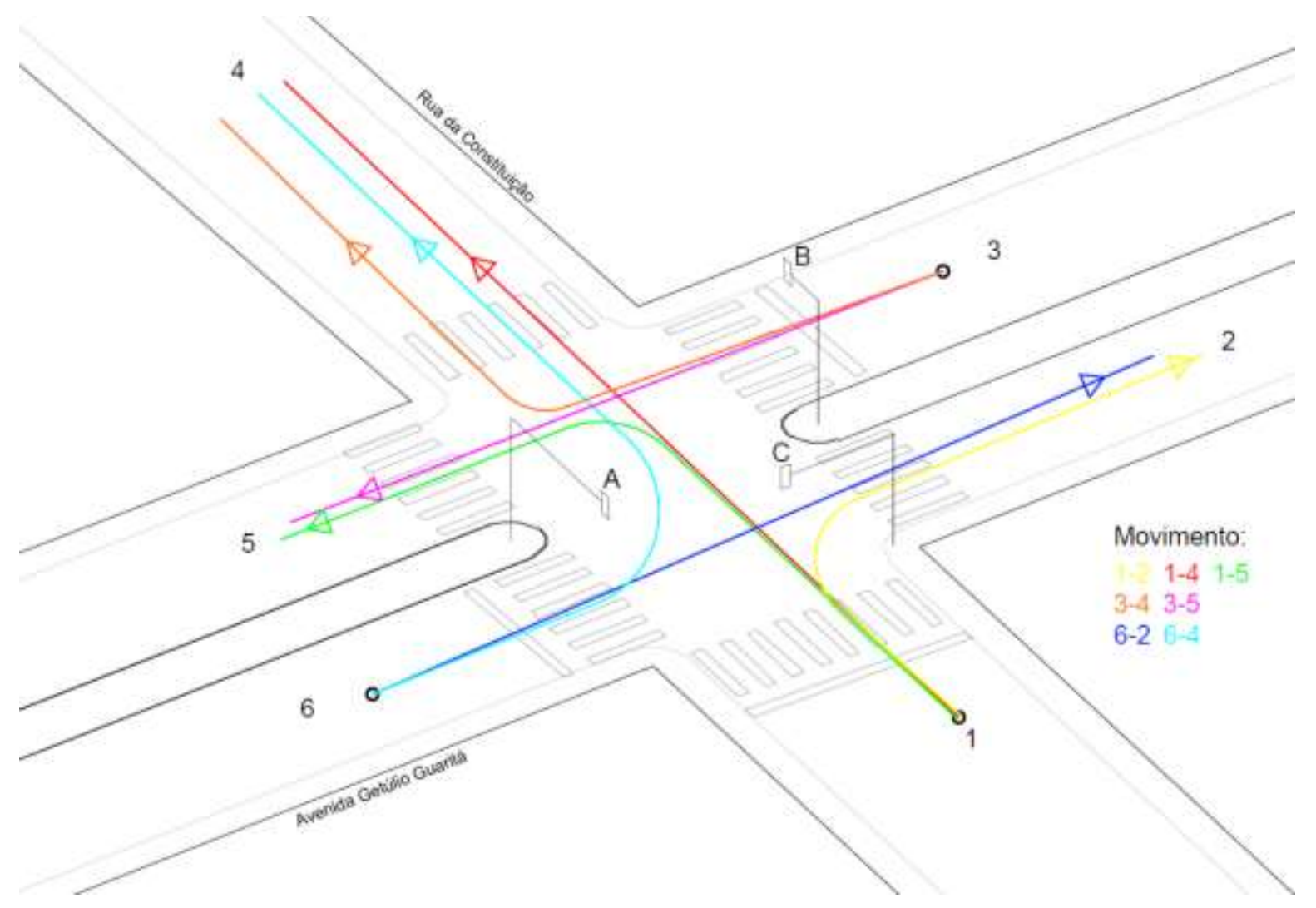

O cenário otimizado foi a redução de 5 segundos no tempo de ciclo de cada semáforo resultando em um novo ciclo de 16 segundos para o semáforo $A$ (que controla o fluxo de veículos que realizam os movimentos 6-2 e 6-4), de 19 segundos para o semáforo $B$ (que controla o fluxo de veículos que realizam os movimentos 3-4 e 3-5) e de 13 segundos para o semáforo $C$ (que controla o fluxo de veículos que realizam os movimentos 1-2, 1-4 e 15). Com isso a velocidade média de deslocamento foi de $31,29 \mathrm{~km} / \mathrm{h}$, a taxa de movimento foi de 0,77 e a soma de veículos em fila atingiu o máximo de 22 veículos. Portanto houve melhora de $6,9 \%$ na taxa de movimento, diminuição do tamanho máximo da fila em 7 veículos (melhora de $24,1 \%$ ) e a velocidade média aumentou em $6,6 \%$.

$\mathrm{Na}$ interseção 2 o maior fator horário de pico foi de 0,97 e aconteceu entre as 19:23 e 20:23 do dia 14 de março de 2018. Através das filmagens foi possível obter o tempo de ciclo dos três semáforos que controlam o fluxo de veículos dessa região. Os ciclos dos semáforos são de 20 segundos para o semáforo $A$ (que controla o fluxo de veículos que 
realizam os movimentos 4-1 e 4-5), de 23 segundos para o semáforo $B$ (que controla o fluxo de veículos que realizam os movimentos 6-1 e 6-3) e de 35 segundos para o semáforo $C$ (que controla o fluxo de veículos que realizam os movimentos 2-1, 2-3 e 2-5) conforme a Figura 2.

Figura 2. Croqui de representação dos movimentos possíveis, distintos por cores, na interseção 2.

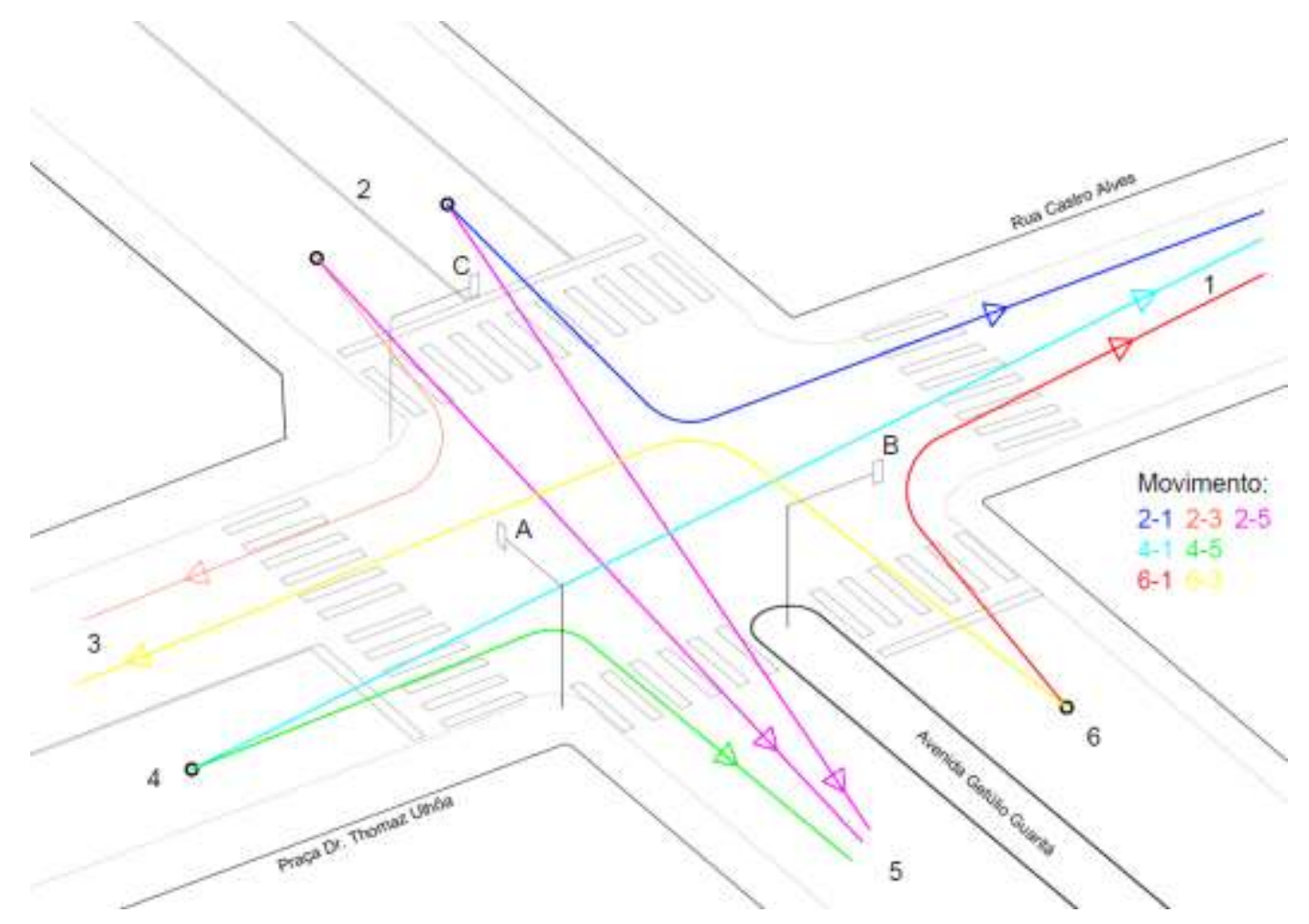

Com esses dados foi possível gerar o cenário atual dessa interseção e obter como velocidade média $29,93 \mathrm{~km} / \mathrm{h}$, taxa de movimento de 0,74 e a soma de veículos em fila atinge um máximo de 32 veículos.

O cenário otimizado foi a redução de 5 segundos no tempo de ciclo de cada semáforo resultando em um novo ciclo de 15 segundos para o semáforo $A$ (que controla o fluxo de veículos que realizam os movimentos 6-2 e 6-4), de 18 segundos para o semáforo $B$ (que controla o fluxo de veículos que realizam os movimentos 3-4 e 3-5) e de 30 segundos para o semáforo $C$ (que controla o fluxo de veículos que realizam os movimentos 1-2 e 1-4 e 15). Com isso a velocidade média de deslocamento foi de $30,92 \mathrm{~km} / \mathrm{h}$, a taxa de movimento foi de 0,76 e a soma de veículos em fila atingiu o máximo de 25 veículos.

Portanto houve uma melhora de $2,7 \%$ na taxa de movimento, diminuição do tamanho máximo da fila em 7 veículos (melhora de $21,8 \%$ ) e a velocidade média aumentou em 3,3\%.

$\mathrm{Na}$ interseção 3 o maior fator horário de pico foi de 0,97 e aconteceu entre as 14:25 e 15:25 do dia 20 de março de 2018.

Através das filmagens foi possível obter o tempo de ciclo dos dois semáforos que controlam o fluxo de veículos dessa região. O tempo de ciclo dos dois semáforos são de 25 segundos tanto para o semáforo A (que controla o movimento 1-3 e 1-4) quanto para o 
semáforo B (que controla o movimento 2-3 e 2-4) segundo a Figura 3.

Figura 3. Croqui de representação dos movimentos possíveis, distintos por cores, na interseção 3.

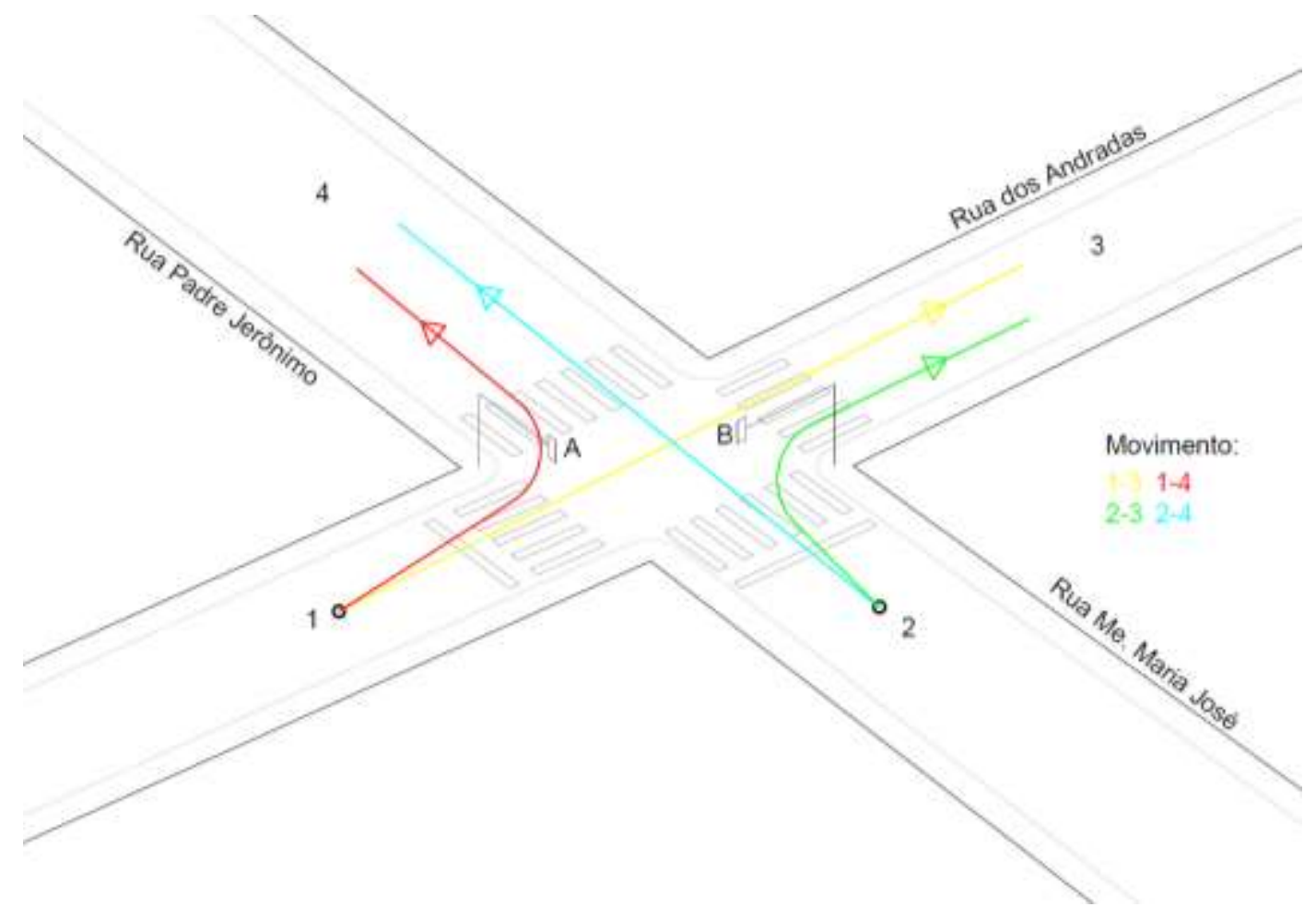

Com esses dados foi possível gerar o cenário atual dessa interseção e obter como velocidade média $20,22 \mathrm{~km} / \mathrm{h}$, uma taxa de movimento de 0,80 e que a soma dos veículos em fila atinge um máximo de 20 veículos.

O cenário otimizado, foi de uma redução de 5 segundos no tempo de ciclo de todos os semáforos da interseção, resultando em um novo tempo de ciclo de 20 segundos para os dois semáforos que controlam o tráfego dessa interseção. Com isso a velocidade média de deslocamento foi de $20,53 \mathrm{~km} / \mathrm{h}$, a taxa de movimento foi de 0,81 e a soma de veículos em fila atingiu o máximo de 15 veículos.

Portanto houve uma melhora de $1,0 \%$ na taxa de movimento, diminuição do tamanho máximo da fila em 5 veículos (melhora de 25\%) e a velocidade média aumentou em 1,5\%.

$\mathrm{Na}$ interseção 4 o maior fator horário de pico foi de 0,97 e aconteceu entre as 11:07 e 12:07 do dia 22 de março de 2018.

Através das filmagens foi possível obter o tempo de ciclo dos dois semáforos que controlam o fluxo de veículos dessa região. Os ciclos dos semáforos são de 23 segundos para o semáforo A (que controla o fluxo de veículos que realizam os movimentos 2-3 e 24) e de 17 segundos para o semáforo $B$ (que controla o fluxo de veículos que realizam os movimentos 1-3 e 1-4) segundo a Figura 4. 
Figura 4. Croqui de representação dos movimentos possíveis, distintos por cores, na interseção 4.

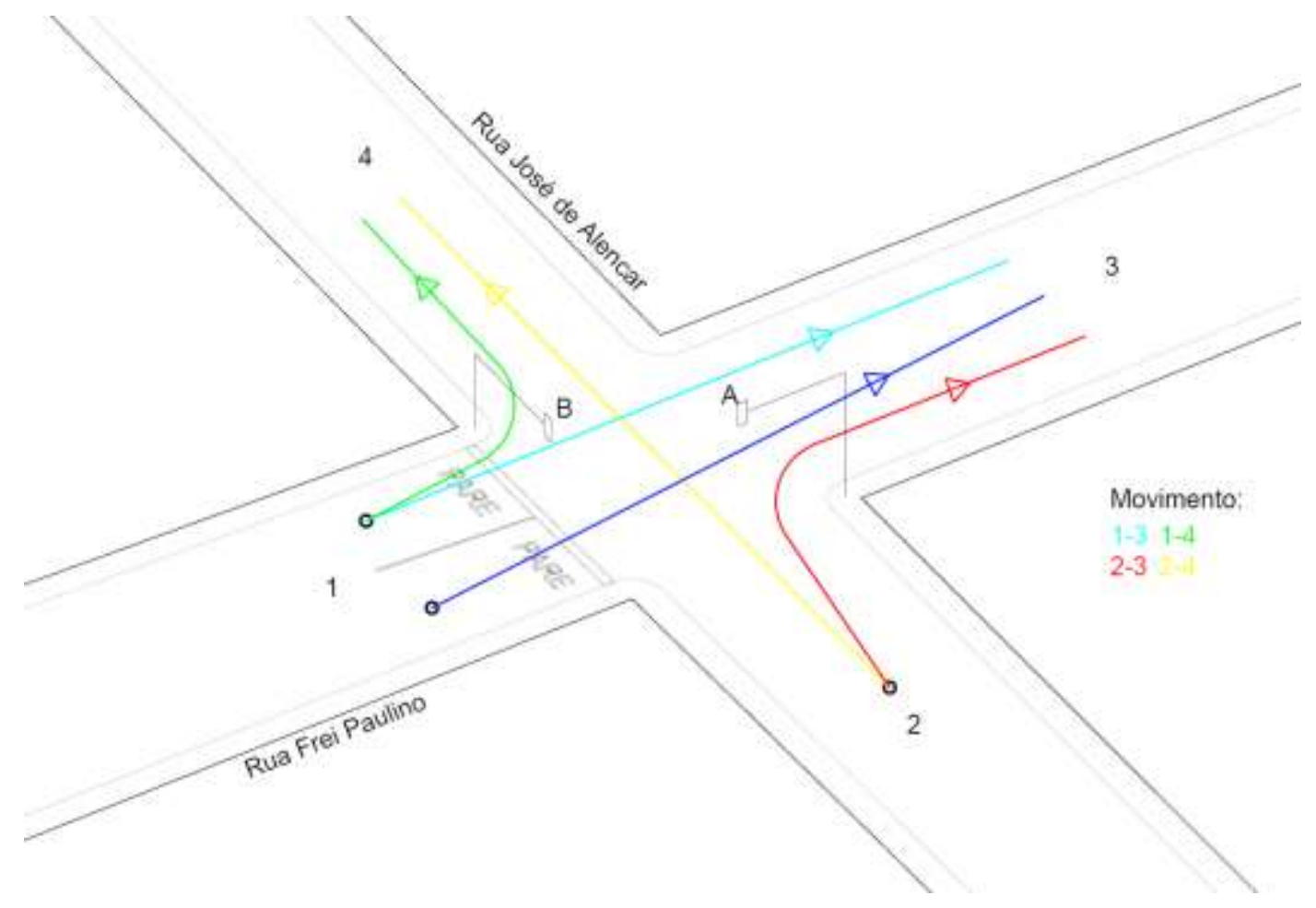

Com esses dados foi possível gerar o cenário atual dessa interseção e obter como velocidade média $33,65 \mathrm{~km} / \mathrm{h}$, uma taxa de movimento de 0,83 e que a soma dos veículos em fila atinge um máximo de 18 veículos.

O cenário otimizado, foi de uma redução de 5 segundos no tempo de ciclo de todos os semáforos da interseção, resultando em um novo ciclo de 18 segundos para o semáforo A (que controla o fluxo de veículos que realizam os movimentos 2-3 e 2-4) e de 12 segundos para o semáforo $B$ (que controla o fluxo de veículos que realizam os movimentos 1-3 e 14). Com isso a velocidade média de deslocamento foi de $33,70 \mathrm{~km} / \mathrm{h}$, a taxa de movimento foi de 0,83 e a soma de veículos na fila atingiu o máximo de 17 veículos.

Com isso, mesmo não havendo mudança na taxa de movimento, o tamanho máximo da fila diminuiu em 1 veículo (melhora de 5,5\%) e a velocidade média aumentou em 0,1\%.

$\mathrm{Na}$ interseção 5 o maior fator horário de pico foi de 0,98 e aconteceu entre as 12:15 e 13:15 do dia 05 de abril de 2018.

Através das filmagens foi possível obter o tempo de ciclo dos dois semáforos que controlam o fluxo de veículos dessa região. Os ciclos dos semáforos são de 26 segundos para o semáforo A (que controla o fluxo de veículos que realizam os movimentos 2-3 e 24) e de 21 segundos para o semáforo $B$ (que controla o fluxo de veículos que realizam os movimentos 1-3 e 1-4) segundo a Figura 5. 
Figura 5. Croqui de representação dos movimentos possíveis, distintos por cores, na interseção 5.

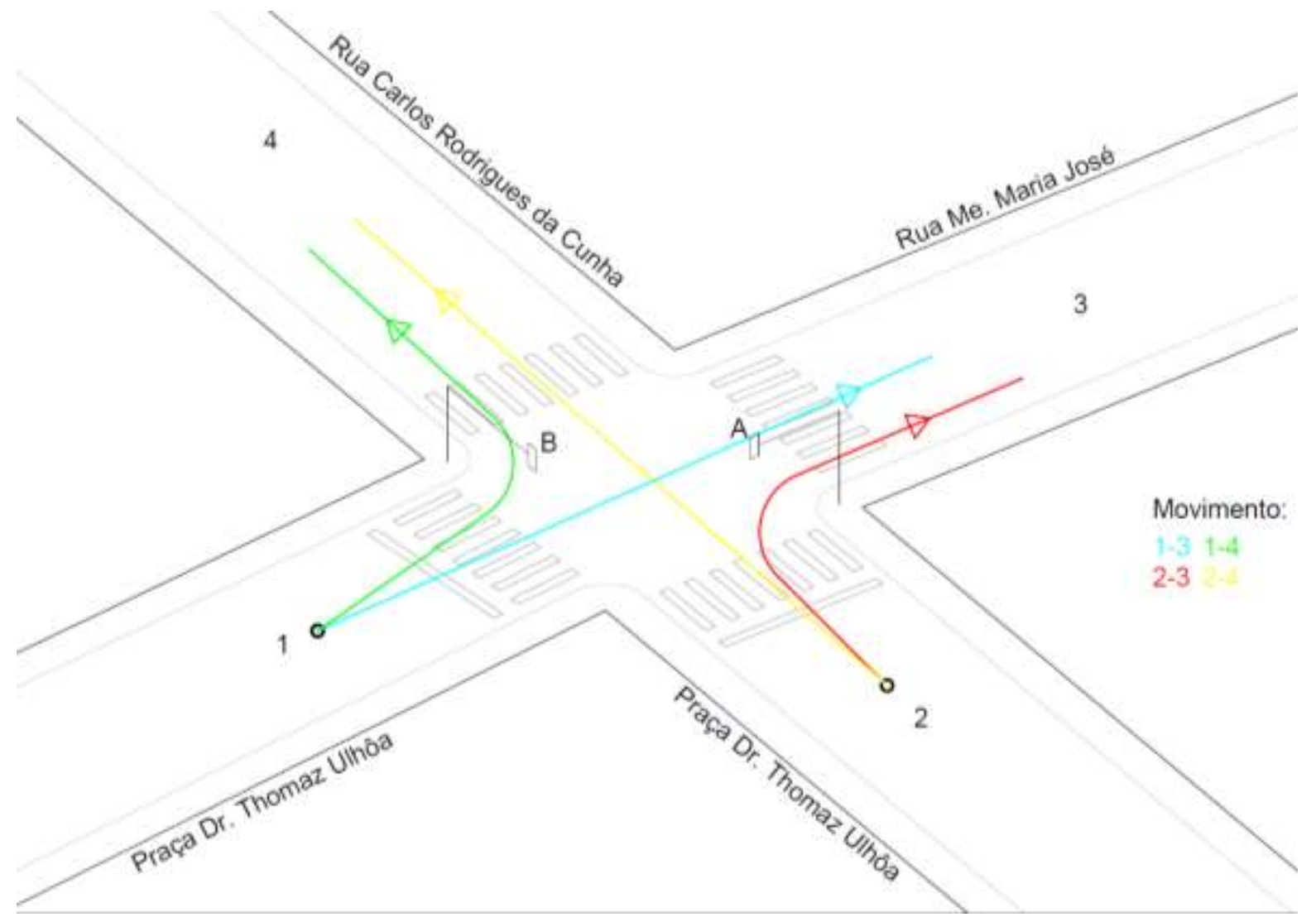

Com esses dados foi possível gerar o cenário atual dessa interseção e obter como velocidade média $29,92 \mathrm{~km} / \mathrm{h}$, uma taxa de movimento de 0,74 e que a soma dos veículos em fila atinge um máximo de 31 veículos.

O cenário otimizado, foi de aumento de 15 segundos no tempo de ciclo do semáforo que controla o segundo maior fluxo de veículos da interseção, resultando em um novo ciclo de 26 segundos para o semáforo A (que controla o fluxo de veículos que realizam os movimentos 2-3 e 2-4) e de 36 segundos para o semáforo B (que controla o fluxo de veículos que realizam os movimentos 1-3 e 1-4). Com isso a velocidade média de deslocamento foi de $30,14 \mathrm{~km} / \mathrm{h}$, a taxa de movimento foi de 0,74 e a soma de veículos em fila atingiu o máximo de 34 veículos.

Portanto a taxa de movimento permaneceu a mesma, o máximo de veículos aumentou em 3 veículos (aumento de 9,6\%), mas a velocidade média aumentou em 0,75\%.

Após análise dos dados coletados em campo e os resultados obtidos nesse trabalho, houve um aumento médio de 2,12\% na taxa de movimento entre as interseções, aumento médio de $2,45 \%$ na velocidade média de deslocamento e diminuição média de $13,36 \%$ da fila máxima de veículos nas interseções e com isso fica evidente que uma modificação no tempo de ciclo dos semáforos existentes pode trazer melhorias para o trânsito da região dado que uma boa gerência do sistema semafórico das cidades promove ganhos do sistema viário como redução dos congestionamentos (CARMO, 2016), pois os três parâmetros que foram analisados (velocidade média de deslocamento, taxa de movimento e quantidade máxima de veículos em fila) foram otimizados em comparação com os do 
cenário atual. Resultados semelhantes foram encontrados por Lacortt, Kripka e Kripka (2013) quando conclui que houve melhoras significativas entre os parâmetros de desempenhos analisados no seu trabalho através da aplicação de modelos matemáticos para otimização de tráfego.

A modificação proposta, diminuição ou aumento do tempo de ciclo, é facilmente realizada e não depende de custos elevados, pois são feitas na programação semafórica dos semáforos e entram em funcionamento logo após o reinicio do sistema que controla o acendimento das luzes do semáforo. Como citado por Lacortt, Kripka e Kripka (2013), pode haver uma melhora significativa nos parâmetros de desempenho apenas aproveitando de melhor forma os recursos já instalados.

\section{CONCLUSÕES}

A área de estudo, por possuir muitos polos geradores de viagens, acaba atraindo um elevado número de veículos para sua região, e o uso incorreto de instalações de controle de tráfego, como o semáforo, pode ser causa direta para o surgimento de congestionamentos. Para amenizar esse cenário o presente trabalho otimizou 5 semáforos presentes em interseções consideradas responsáveis por escoar o fluxo de veículos.

Entre os cenários otimizados a redução de 5 segundos no tempo de ciclo dos semáforos foi o cenário que mais apareceu (4 entre 5) sugerindo que o tempo de ciclo está próximo de um tempo ideal para o fluxo de veículos de cada interseção. Apenas na interseção 5 o cenário otimizado foi o aumento de 15 segundos no tempo de ciclo do semáforo que controla o segundo maior fluxo de veículos e esse fato pode ser entendido como uma necessidade de aumentar o tempo de escoamento de veículos que chegam naquela interseção.

Portanto os resultados encontrados estão dentro de parâmetros compatíveis com a realidade e, para alcançar esses resultados, as medidas que devem ser tomadas são de baixo custo e causam pequenos distúrbios nas interseções.

\section{AGRADECIMENTOS}

Os autores agradecem à Fundação de Amparo à Pesquisa do Estado de Minas Gerais - FAPEMIG, pela concessão de recursos financeiros via Chamada Universal de Pesquisa e de bolsa de Iniciação Científica.

\section{REFERÊNCIAS}

CARMO, A. R. Programação Semafórica: Uma Proposta de Otimização Apoiada em um Modelo Geo-Temporal. 2016. 141 f. Dissertação (Mestrado em Engenharia Civil) Universidade Estadual de Campinas, Campinas, SP, 2016.

CONTRAN. Conselho Nacional de Trânsito. Manual Brasileiro de Sinalização de Trânsito Volume V - Sinalização Semafórica. Brasília: CONTRAN, 2014. 313 p.

CUCCI NETO, J. Semáforo: ser ou não ser inteligente? Uma comparação entre o controle semafórico em tempos fixos e o em tempo real. 2015. Disponível em:

http://meusite.mackenzie.br/professor_cucci/texto2.pdf. Acesso em: 05 abr. 2018. 
DENATRAN. Departamento Nacional de Trânsito. Frota de veículos, por tipo e com placa, segundo as Grandes Regiões e Unidades da Federação - Dezembro/2017. Brasília, 2017. Disponível em:

http://www.denatran.gov.br/images/Estatistica/RENAVAM/2017/Dezembro/Frota_Reg_UF_Tipo_modelo_DEZ_2017_2.xls. Acesso em: 01 abr. 2018.

DENATRAN. Departamento Nacional de Trânsito. Frota de veículos, por tipo e com placa, segundo as Grandes Regiões e Unidades da Federação - Janeiro/2007. Brasília, 2007. Disponível em: http://www.denatran.gov.br/images/Estatistica/RENAVAM/2007/Frota2007.zip. Acesso em: 01 abr. 2018.

DNIT. Departamento Nacional de Infraestrutura de Transportes. Manual de Estudos de Tráfego. Rio de Janeiro, 2006. 384 p.

HC-UFTM. Hospital de Clínicas da Universidade Federal do Triângulo Mineiro. Carta de Serviços ao Cidadão. Uberaba, 2017. 39p.

KNEIB, E. C.; TACO, P. W. G; SILVA, P. C. M. S. Polos geradores de viagens e mobilidade: a evolução dos conceitos e da consideração dos impactos gerados. Revista dos Transportes Públicos, v. 121, p. 65-80, 2009.

KNEIB, E. C.; SILVA, P. C. M.; PORTUGAL, L. S. Impactos decorrentes da implantação de pólos geradores de viagens na estrutura espacial das cidades. Transportes, v. 18, n. 1, p. 27-35, 2010.

LACORTT, M.; KRIPKA, M.; KRIPKA, R. M. L. Modelos Matemáticos para Otimização do Tráfego Urbano Semaforizado. Tema, v. 14, n. 3, p.359-372, 2013.

MENDES, E. O.; SORRATINI, J. A. Polo gerador de viagens: análise de um terminal urbano de passageiros anexo a um centro comercial. Brazilian Transportation Planning Society Journal of Transport Literature, v. 8, n. 3, p. 290-307, 2014.

PORTUGAL, L. S. Simulação de tráfego: conceitos e técnicas de modelagem. Rio de Janeiro: Interciência, 2005. 197 p. 